\title{
Conceptualizing Relational Resources as Critical Factor for IT Outsourcing Success
}

\author{
Paolo Popoli ${ }^{1}$ \\ ${ }^{1}$ Parthenope University of Naples, Naples, Italy \\ Correspondence: Paolo Popoli, Parthenope University of Naples, Department of Management Studies and \\ Quantitative Methods, Via Generale Parisi 13, Naples, Italy. Tel: 39-347-331-6034. E-mail: \\ paolo.popoli@uniparthenope.it
}

Received: July 26, 2017

doi:10.5539/ijbm.v12n10p43
Accepted: September 10, $2017 \quad$ Online Published: September 17, 2017

URL: https://doi.org/10.5539/ijbm.v12n10p43

\begin{abstract}
The relational resources represent key assets for outsourcing success. Achieving full potential in the development and exploitation of relational resources in outsourcing can be understood as occurring in two closely intertwined phases: i. during the choice of the provider; ii. through the governance of the relation that develops over the execution of the contract. The current paper aims to provide conceptual insights into these two phases, as they apply to the particular area of companies' IT outsourcing. A first objective is to illustrate the role of relational resources in determining the ultimate degree of success in IT outsourcing and to discuss its potential as an "instrument to address risk". A second objective is to outline managerial criteria for correct choice of the IT provider and for appropriate direction of client-vendor relations over the course of the resulting contract execution. The main findings of this study show that the paradigmatic shift from a transaction-based outsourcing to a partnership-based outsourcing gives centrality to the contract management and on-going management. On this point, relational resources have become a critical factor for IT outsourcing success, and they have to be considered as a tool to address the risks of IT outsourcing. Concerning the managerial implications the main finding is the need to use the "relational requisites" rather than "subjective requisites" in the evaluation and choice of potential IT provider.
\end{abstract}

Keywords: IT outsourcing, relational resources, partnership-based outsourcing, contract management

\section{Introduction}

Since the late 1980s the outsourcing of IT services has seen enormous growth (Beasley, Bradford, \& Dehning, 2009) and remarkable change in objectives, content and forms (Popoli, 2011). Initially, the externalization of IT activities and functions was primarily tactical in character. The primary aim was to obtain cost savings (outsourcing for cost saving), and secondly to keep abreast of technological evolution and the development of competencies that individual companies could not resolve alone (Quinn, \& Hilmer, 1994). Given these aims, companies also developed the first practices of "offshoring" (Mol, van Tulder, \& Beije, 2005; Larsen, Manning, \& Pedersen, 2013; Schmeisser, 2013). Such international outsourcing was primarily intended to exploit cost differentials, particularly with respect to emerging nations gathering the first yields from investment in technological knowledge (India, the Philippines, Brazil, Ireland, etc.).

Subsequently IT outsourcing became a strategic choice (Quinn, \& Hilmer, 1994; Gobble, 2013; Lacity, \& Willcocks, 2014; Zhang, \& Kurien, 2017). IT structures were increasingly required to render management processes not only more efficient and economical, but also more innovative and flexible for strategic purposes. IT structures became more critical in the implementation of business logic, capable of conditioning the effectiveness and efficiency of processes for creation of company value (outsourcing for "value creation"). IT implementation was no longer simply a factor in the support of the value chain. Thus we now speak of "strategic IT outsourcing" to indicate the strategic aspect of outsourced activities, and "tactical IT outsourcing" to indicate the "commodities" of IT functions and activities.

The changes in objectives and aims for IT outsourcing brought about parallel changes in the relationships developed between client and vendor. The paradigm shifted from transaction-based outsourcing to relationship-based or partnership-based outsourcing (Lee, 2001; Qi, \& Chan, 2012). This led to the adoption of new systems of governance, control and coordination. Relations were no longer centered exclusively on 
contracts alone, which became insufficient to regulate relations that had become much more complex. The new systems involved relational governance, governance through organizational processes and structures, and governances based on systems of risk-reward incentivization (Behrens, 2006). This evolution in governance systems became necessary in all IT outsourcing where the primary or parallel aim with respect to cost saving was the generation of new common knowledge, founded on the exchange and sharing of knowledge (Bahli, \& Rivard, 2005; Ikediashi, Ogunlana, Boateng, \& Okwuashi, 2012; Larsen et al., 2013).

However the changes in the externalization of IT activities and processes also generated significant cases of unsuccessful outsourcing and increasing instances where the client companies "backsourced" activities and processes to their own organizational structures (Earl, 1996; Gonzales, Gasco, \& Llopis, 2010). These cases occurred for various reasons: worsened customer service for the client company; higher costs than predicted; failure of the provider company to understand the client's business logic; lack of flexibility in the offer of IT services; technological changeovers that were more difficult than expected, and failure of the provider to respect the service levels agreed. In some cases the client company's decision to backsource was a response to their observed loss of competent and qualified human resources. These causes of failed outsourcing could perhaps have been avoided if the principles and practices of risk management had been more active among the companies, particularly in the stages of contract management and on-going management. These stages serve in the initial construction and subsequent development of conditions of mutual trust, cooperation, and harmonization in client-vendor strategies and objectives (Lee, Miranda, \& Kim, 2004; Qi, \& Chan, 2012). In these stages the relational resources held by the both the outsourcer and outsourcee play a crucial role. In fact very often the companies dedicate great emphasis and time to the initial stage of the outsourcing process, meaning the decisions as to whether and how to outsource and what services, functions or processes to assign. Much less attention is given to planning all the aspects of client-vendor relations, which is where many of the financial, strategic and organizational risks arise.

The present paper descends from the context just outlined. The objective is to illustrate the centrality of relational resources in IT outsourcing, particularly the practices for externalization of functions or internal processes with an elevated impact on the value of the outsourcing company, which are closely related to the core business (strategic IT outsourcing). In these cases the need for relationality and partnership is very high, since the success of outsourcing in these situations is based on the sharing and exchange of knowledge (Bahli, \& Rivard, 2005; Ikediashi et al., 2012; Larsen et al., 2013). The relationship is long term in character and requires greater flexibility and coordination in strategic, organizational and operational terms.

Many studies on outsourcing focus on why, how and what firms determine to outsource (King, 2005; Schmeisser, 2013), but few studies have examined relational resources in terms of risk management. The value of this paper lies in two areas: i) it examines the use of relational resources as an instrument to address the risks of IT outsourcing; ii) it identifies results that can be expected from the adoption of appropriate criteria for provider selection and from systems for governance of relations that go beyond simple contract control.

Methodologically, this paper analyses and discusses the main literature on IT outsourcing written in the last decades, providing insights on the governance systems of IT outsourcing from a relational perspective. Therefore, this paper is conceptual in nature, and strives to improve knowledge on this specific field through a critical analysis of the principles of the contract management and of the on-going management.

The next section of the paper analyses the theoretical frameworks that focus on social and behavioral problems in business-exchange relations, from which we identify the importance of relational resources in company management. Sections 3 and 4 deal with the paper's central theme: the consideration of relational resources as an "instrument to address risk", and the proposal of conceptual insights on managerial criteria for the correct choice of the IT provider and the appropriate direction of client-vendor relations over the course of the resulting contract execution. In particular, our insights concern broadening the evaluation and choice of potential providers from the traditional "subjective requisites" to now include "relational requisites". Finally, in Section 5 we identify the conditions that can determine whether the outsourcing contract serves as an "instrument to address risks" or "generators of risks". The concluding section of the paper indicates further research directions.

\section{Theoretical Frameworks}

In this paper, the analytical perspective adopted in considering IT outsourcing is the partnership-based or relationship-based paradigm. This approach is clearly more appropriate than the transaction-based paradigm in all cases where the aims of outsourcing concern the exchange and sharing of knowledge, as occurs in IT strategic outsourcing (D.C. Chou, \& A.Y. Chou, 2011; Yeo, \& Saboori-Deilami, 2017).

Scholars have applied various theories that address the relational aspects of client-vendor exchange relationships. 
These have often been applied in studies on outsourcing, in attempts to better understand the decisive factors for the potential success of outsourcing operations. The principle theories applied have been "agency theory" and "relational exchange theory", both of which concentrate on the specific issue of relational resources.

Agency theory (Williamson, 1985, 1986; Eisenhardt, 1989) analyzes the relations of business exchange in terms of two main factors: i) information asymmetry, where the actor delegating the execution of an activity (the principle) is in a weak situation with respect to the actor being delegated to carry out the activity (the agent); b) ii) risks of opportunistic behavior, through which the agent could attempt to exploit the information asymmetry in his favor. The occurrence of these factors raise a series of potential problems in the agency relationship, since the principle is not always able to control the behavior of the service provider and it is in fact very costly to determine what the agent is doing (Aris, Arshad, \& Mohamed, 2008). In addition, the contract is defined under the limits of available information and understanding (bounded reality) and thus cannot cover all contingencies and future behaviors (Das Aundhe, \& Mathew, 2009). Studies have demonstrated that the most common opportunistic behaviors on the part of vendors are shirking, poaching and renegotiation (Aron, \& Liu, 2005). Such behaviors are based on information asymmetry in favor of the vendor and the impossibility for the principle to control the exchange. Shirking consists of deliberate underperformance on the part of the service provider, while still demanding payment as if the tasks were completed according to terms. Poaching is the attempt to achieve extra revenue by misusing the client's critical business data. Renegotiation is the request by the service provider for greater payment than appropriate: the provider outsmarts the client, opportunistically exploiting his much greater knowledge of IT services. Hence the focus of agency theory is on how to define the most efficient contract possible to govern the agency relationship, which would permit the principle to have the maximum possible control over what the provider does in terms of quality of services, and at the same time permit the agent to satisfy the principle through achievement of his specific objectives (Logan, 2000).

Relational exchange theory, or RET, was introduced by MacNeil in the 1980s $(1985,1986)$. This conceptual approach focuses on the relational norms created in exchange relations, which constitute the base elements of efficiency in contract governance between the client and vendor. Relational norms are specific behaviors that subjects in transactions assume, to identify, maintain and develop relations under conditions of present and future equilibrium, even during the inevitable situations of contractual insufficiency. The specific relational norms of interest are: flexibility, information exchange and solidarity (Gottschalk, \& Solli-Saether, 2006). The role of these norms is to complement and strengthen the contractual norms, which cannot alone govern the unforeseeable future contingencies that could negatively influence the relationship (Goles, \& Chin, 2002).

RET concepts are based in social theories, most specifically on the further development of "social exchange theory" (SET) as originally introduced by Homans in 1958. Social exchange theory identified the existence of social and behavioral dimensions in relations between business subjects, in addition to the dimension of pure economic exchange. SET begins from the premise that the aim of the two actors in creating a voluntary exchange relationship of is to obtain benefits that are clearly greater than the related costs. However SET illustrates that such relationships are not limited to mere economic exchange and that they also contain elements of social exchange, such as trust, communication, knowledge sharing, cooperation, and sharing of both risks and benefits (Yanhong, 2011). The actors create such exchange relations when in examining the potential behaviors of their counterpart they perceive possibilities to achieve common benefits (Thibaut, \& Kelley, 1959; Homans, 1961; Emerson, 1972).

In the subsequent sections of the paper we address three central issues in IT outsourcing, in the light of the theories summarized above: i) selection of the provider; ii) contract management, and iii) ongoing management. RET is particularly related to the stage of selecting the most appropriate provider, providing assistance in resolving the problems of knowing the provider in terms of capacity to adopt relational norms (Joshi, \& Stump, 1999; Gottschalk, \& Solli-Saether, 2005). Agency theory is firstly relevant to the stage of contract management, meaning the design and management of the contract that governs the relationship. In particular it supports the design of contract elements that favor the creation and maintenance of a climate of reciprocal trust, and strengthen the contract through the addition of systems for governance of the relationship. Secondly, agency theory is also relevant to stage of monitoring the relationship during contract execution. In this stage it assists in defining the appropriate means for maintenance of long and short-term equilibrium between the needs of the two parties: on the client side, the need for guarantees of high levels of service; on the vendor side, the need for agreement that the client's objectives have been satisfied in full (Eisenhardt, 1989; Logan, 2000; Poppo, \& Zenger, 2002). 


\section{Relational Resources as an Instrument for Addressing Risks}

In understanding the value of relational resources in IT outsourcing, a first necessary consideration is that the relational resources required depend above all on the type of outsourcing intended, particularly on the externalized items and the aims that the client intends to pursue (Nam, Rajagopalan, \& Chaudhury, 1996; Kishore, Rao, Nam, Rajagopalan, \& Chaudhury, 2003). An important distinction is thus made between tactical or operational outsourcing and strategic outsourcing, which indirectly signify outsourcing "for cost savings" and outsourcing "for value creation". It is clearly evident that as the strategic content of the relationship grows there is also a growing need to govern the relationship on a partnership basis.

Thus if the object of externalization is a strategically "non-critical" activity or process, the relation between client and provider can be classified as a lower level of collaboration and partnership. The expected performance is predefined in the contract and can easily be measured along defined parameters. The subsequent stage of managing the relationship consists primarily of "control" that the performance actually provided respects the technical and performance terms identified in the contract.

The situation is the opposite where the objects of externalization are activities, functions or processes of high strategy value on strong impact on firm business. In this case the client expects to receive contributions from the provider that increment the firm's capacities in innovation and value-creation. Such needs will best be satisfied through a partnership-based approach that inserts processes for the generation of new, shared knowledge (knowledge development).

Given these premises, in our opinion the value of relational resources should be reconsidered in the perspective of risk management, and for this aim we consider it useful to first of all to recall that the process of IT outsourcing can be subdivided in elementary stages, as seen in Figure 1. Each one of these steps implies the assumption of choices on the part of the firm. Each entails risk factors that can determine lack of success in the outsourcing, to greater or lesser extent. As a whole, the series of steps requires specific managerial competencies capable of identifying what strategic, organizational and economic profiles are concerned in the outsourcing choice, thus permitting the firm to exploit the maximum possible advantage while minimizing "probabilities" and "impacts" of the various risk factors on the business results.

Figure 1 illustrates the process of outsourcing as a sequence of elementary stages. The six steps can be synthesized under three macro-stages, corresponding to three distinct but closely interdependent moments in the governance and control of relations:

- Formulating the choice (governance);

- Implementing the choice (ex ante management);

- Managing the relationship (management).

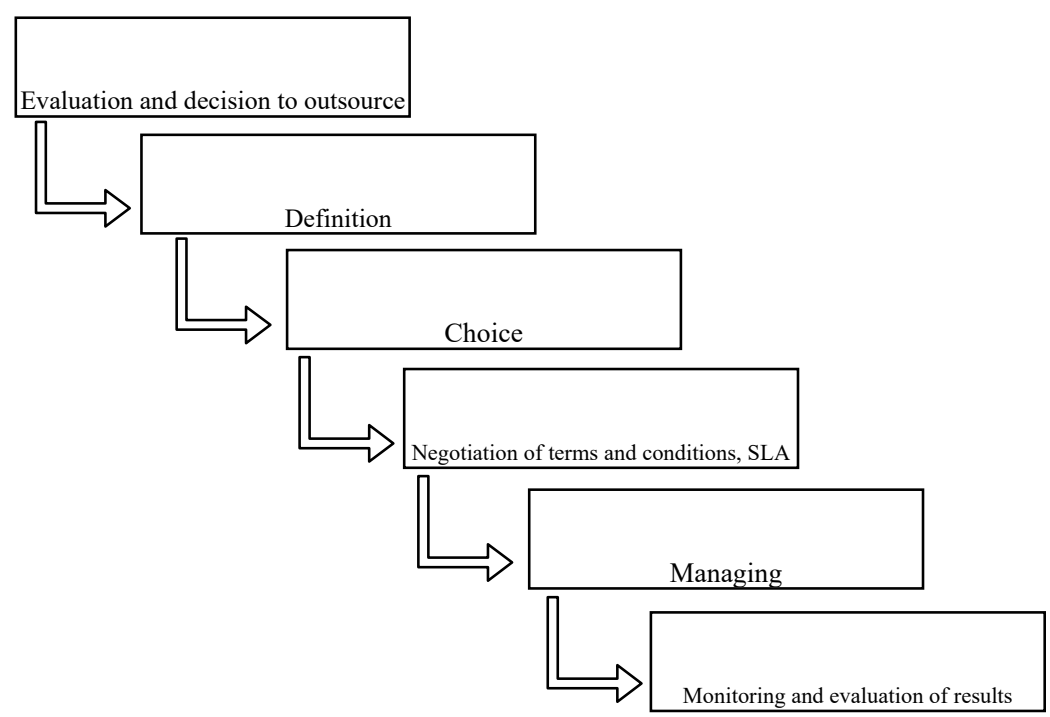

Figure 1. The outsourcing process 
In Figure 2 we synthesize the different elementary steps of outsourcing in three maxi-stages of governance and control. The schema we provide assists us in rendering it more clear and evident which are the areas of the outsourcing process where relational resources express their value. We will observe how relational resources enter into play in the two stages of "choice implementation", meaning when the firm chooses the provider and first regulates the developing relationship between client and vendor, and in the stage of managing the relationship, meaning in the operative stage of executing the contract (ongoing management).

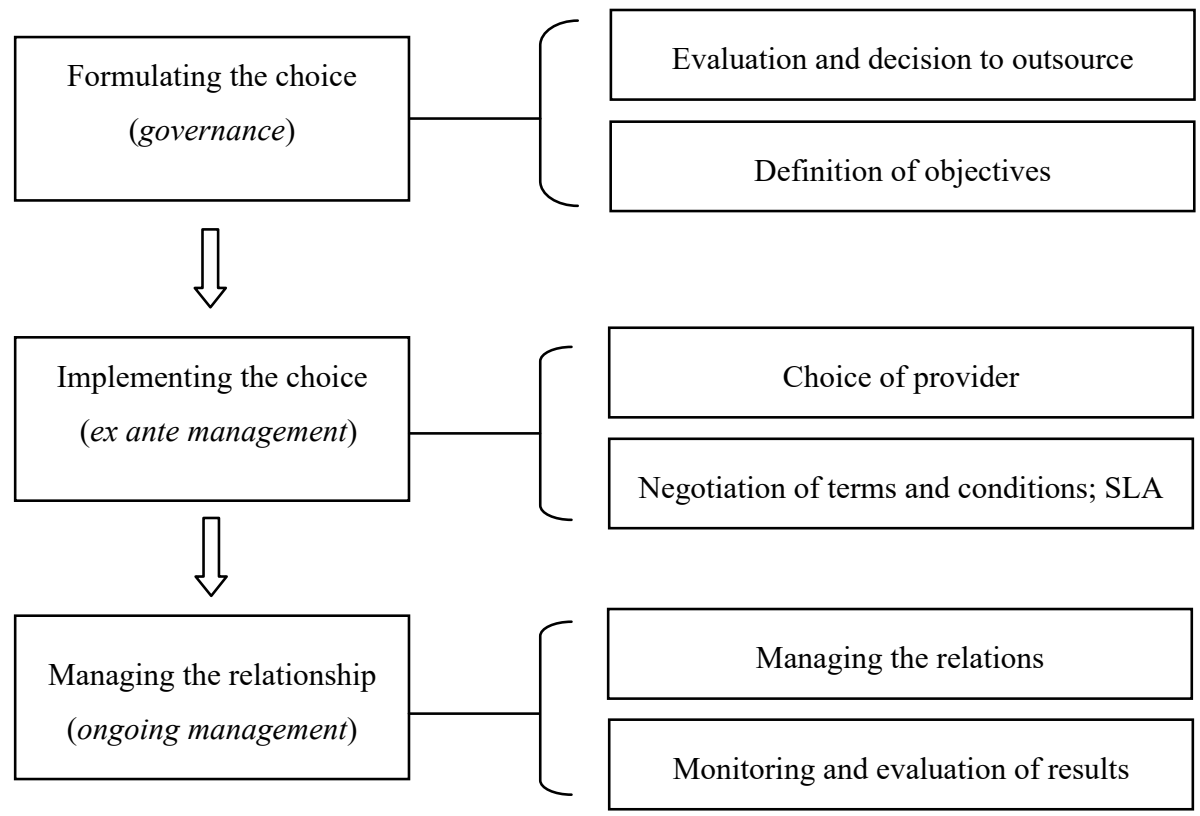

Figure 2. Outsourcing macro-stages

The identification of these macro-stages permits better observation of the outsourcing process for risk management. It creates a link between relation resources and some of the risks through a reasoning process. If we exclude the initial risks related to erroneous externalization of an item that should not have been externalized, then the remaining risks in IT outsourcing are situated in the two macro-stages of implementing the choice and the third of managing the relationship, meaning in the stages where relational resources can play a role. In fact the major risks in outsourcing are identified in a well-known list produced by Berthélemy (2003), developed through empirical examination of approximately 100 cases of unsuccessful outsourcing in European and North American firms, as follows:

1. Outsourcing activities that should not be outsourced;

2. Selecting the wrong vendor;

3. Writing a poor contract;

4. Overlooking personnel issues;

5. Losing control over the outsourced activity;

6. Overlooking the hidden costs of outsourcing;

7. Failing to plan an exit strategy.

These "seven deadly sins of outsourcing", to use Berthélemy's term, can be associated with specific moments in the outsourcing process. In particular, given our schema of maxi-stages in Figure 2, the associations are as follows:

- Formulating the choice: Error 1;

- Implementing the choice: Errors 2,3,4,7;

- Managing the relationship: Errors 4,5,6.

From all the above it becomes evident that the majority of risks in outsourcing can be addressed through greater relational resources, through which to evolve the client-vendor relationship towards a partnership relation, 
beginning with the moment of the selection and choice of a provider. It is from this observation that we derive our conceptual framework of considering relational resources as an instrument for risk management. Our thesis is that many of the risks in outsourcing can be minimized through: a) selection of a provider capable of developing a partnership relationship that meets defined conditions; b) structuring the partnership relationship through the adoption of systems of governance that are not only embedded in the contract, but that also provide formal and informal mechanisms of coordination and strategic and organizational integration between the client and vendor.

\section{The Choice of a Provider}

The choice of a povider is usually identified as one of the most critical moments in the outsourcing process. This is in part because of the significant difficulties involved in cases of unsatisfactory results, when the client must substitute or even reintegrate the externalized activity, process or function in the original organization (backsourcing).

The process leading to the choice of a provider has been analyzed extensively. It is generally diagrammed as a series of steps to be followed in sequence in order to minimize the risks of failure in the relationship (Figure 3).

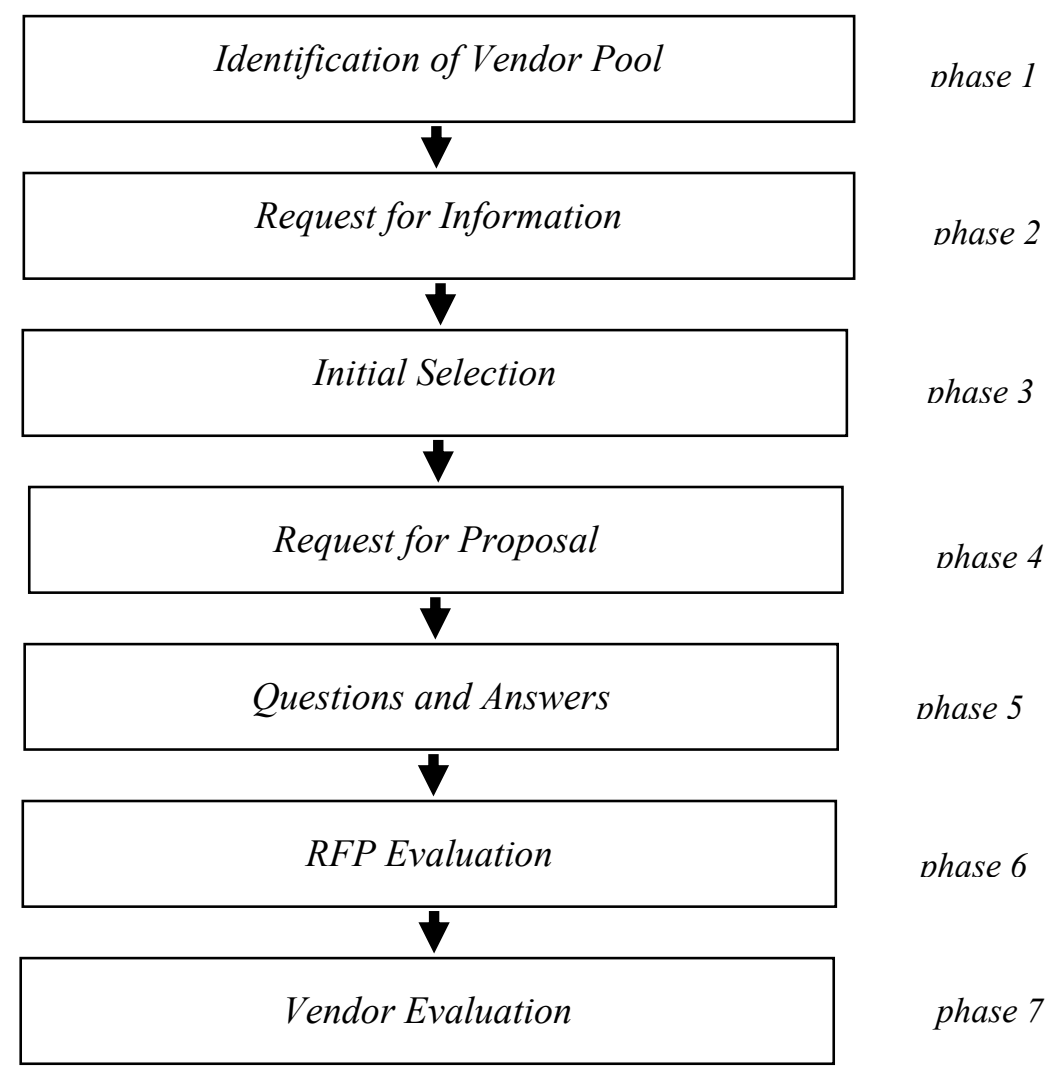

Figure 3. Process for selecting a provider

Steps one and two (analysis of the provider market and requests for basic information) represent the first moments in the evaluation of potential providers, when the client ascertains that potential providers respond to the firm's economic-financial, technological, organizational and strategic requirements. These ex ante evaluations of are often conducted by developing a short list of elements to be verified, and serve to categorize the market of suppliers. Based on the results of these steps the client proceeds to an initial selection of one or more providers for further analysis and evaluation.

The next step is to request the initial selection of potential provider(s) to provide a technical-financial proposal, in terms specified by the client. The provider must indicate their proposed response to all the most significant elements of the contract under the items specified by the potential client. This includes: the type and characteristics of services, the standards and criteria for measurement of performance, means for determining the price, means for interface between the two firms, as well as innovative ideas and potential improvements over what was initially requested by the client (Greaver, 1999). 
This first series of steps all serve in the initial configuration of the contents of the outsourcing relationship, which are then further integrated or modified depending on the answers to the client's requests for deeper information or clarification (questions and answers). With the "answers" received, the client firm then proceeds to the final evaluation of the proposals and thus the definitive ex post evaluation of the providers, leading to the choice of the partner.

Various authors have advanced lists of criteria to use in the process of choosing the provider. These tend to be articulated differently: i) for different market segments of providers (Wind, \& Cardozo, 1974; Kamanth, \& Liker, 1994); ii) according to the strategic relevance of the object for outsourcing and the risk level in the relationship (Kraljic, 1983), and iii) according to the type of client-provider relationship intended (operative versus strategic; short versus medium-long term; transactional versus relational).

The variables proposed for use in the selection process refer to "subjective requisites" demanded of the potential provider, such as: business-financial solidity; specific competencies and technologies of IT infrastructure; a certain portfolio and prices of services, including certain qualities or degrees of innovation; experience in the sector, and reputation in the market in (reliability, security, transparency, etc.).

The emphasis on these subjective requisites for the business practice of the provider is revealed in two empirical studies identifying the criteria most frequently actually applied by firms in the choice of vendors for IT outsourcing. An investigation by the Cutter Consortium (2001) proceeded by interviewing the managers of "outsourcee" firms that had engaged in outsourcing relationships. Interestingly, according to the manager's reports, "they selected the appropriate vendor only $41 \%$ of the time". Tab. 1 provides indicates the average frequency with which the client firms had applied specific criteria in the selection of their provider.

Table 1. Criteria applied in provider selection (Cutter Consortium, 2001)

\begin{tabular}{lc}
\hline Technological capacity & $48 \%$ \\
\hline Previous working relationships with the client & $41 \%$ \\
Proven experience & $37 \%$ \\
Reputation & $36 \%$ \\
Price & $30 \%$ \\
Stability of the provider business & $28 \%$ \\
Understanding of the client firm's needs & $24 \%$ \\
Recommendation by a consultant & $23 \%$ \\
Propensity and commitment to quality & $21 \%$ \\
Considerations concerning times for service provision & $19 \%$ \\
Provider's knowledge of the client firm's business sector & $18 \%$ \\
Localization & $18 \%$ \\
\hline
\end{tabular}

A second study by Aris et al. (2008) produced similar results, again indicating that client firms tend to focus on subjective requisites in the choice of the potential provider, as shown in Tab. 2.

Table 2. Factors in selection of service provider (Aris et al., 2008)

\begin{tabular}{lc}
\hline \multicolumn{1}{c}{ Factors } & Ref \\
\hline Reputation and Performance & 17 \\
Experience & 54 \\
Financial stability & 54,61 \\
Personnel assigned & 6 \\
Access and ability to adopt to latest technology & 6 \\
Practices of standard, polizie and procedure & 12,21 \\
Practices of security & 12,21 \\
Responsibility towards disaster recovery plan & 53 \\
Usage of third party & 25 \\
\hline
\end{tabular}

\subsection{From "Subjective" Requisites to "Relational" Requisites}

The two empirical investigations reported above, as well as many other studies in the literature, show that client firms' evaluation of potential providers tends to deal exclusively with subjective variables. The firms appear to ignore all the variables that express the true potential of the provider to achieve full partnership-based outsourcing, 
meaning full strategic and organizational integration with the client firm. Even when the client firm examines the providers' strategies, management capacities, or potentials for development of future business, it appears that the evaluations lack or are weak in considering a series of variables that refer to: i) the capacities for integration of the structures, procedures and cultures of the two subjects entering the relationship; ii) the compatibility of the objectives pursued by the two parties; iii) the potentials for development of a true strategic partnership.

The subjective requisites typically applied in the analysis of providers are clearly important, but our belief is that alongside these there should also be consideration of the "relational requisites" for the provider. We identify two questions concerning governance and management of risk in outsourcing as being particularly important:

- The questions as to whether and how the respective value chains of the two parties in the relationship are integrated, and in particular whether the client firm represents a significant, logical client of the provider firm;

- The question as to whether the provider demonstrates true capacity and availability to develop a partnership relationship with the client firm - in particular if the provider's approach to the market is aimed at the simple "stipulation of a contract" or if it has mid-long term aims for the construction of partnership-type relationships involving cooperation and trust.

Concerning the first question, one of the most important conditions for the outsourcing relationship to express its full potentials and reduce risks of failure is the potential for integration of the two value chains. The activities, processes and functions entrusted to the provider should be consistent with and enter within the provider's value chain, and thus in it's normal business. It is only when the object of outsourcing belongs to the core business of the provider that there can be adequate provision for the client-provider relationship to attain a win-win logic, with advantages and benefits accruing to both parties in the relationship.

The possibilities of developing a partnership relationship would be completely blocked by incongruities in the two value chains. The failure in strategic alignment of the two firms would block the achievement of synergies and the conditions for stability, as well as the future development of the relationship in new directions. In the case where the value chains do not match, the relationship will inevitably develop as a simple commercial exchange. The relationship would essentially be anonymous and likely of brief duration.

One of the crucial questions for the client firm should be if the activity, process or function to be externalized pertains to the core business of the potential provider, or if it is simply something the provider is able to do given its production technologies and market strategies.

The client must also distinguish whether his firm, and the product or service being requested from the provider, match the portfolio of the provider's typical offer or if they vary to some minor or possibly radically new extent. If the object outsourced matches the provider portfolio then the provider can draw on experience and technological, organizational and management knowledge that has already been consolidated through its operations. The provider can exploit cost economies linked to a higher degree of standardization in the product or service being provided. In this case the provider's activity will take on the character of the "one product for many" approach typical of competitive strategies based on cost leadership.

Such strategies are typical of contractual relations based on commercial exchange (transactional approach), where the object is an activity, function or service that can provide only marginal effects in the client's processes of value creation. In this case, the client will perceive all the economic advantages that derive from exploiting the investments already made by the provider, obtaining higher levels of performance and lower costs compared to what could be achieved by internalization. In summary, the client will obtain advantages from the provider's competencies and resources, to apply in improvement or innovation in its business.

If the product or service requested from the provider is outside its historic business then new investments will be necessary in technology, human resources and professional skills. The provider must evaluate the investments demanded according to the usual business principles and techniques (Williamson, 1986, 1996; Stuckey, \& White, 1993; Bensaou, 1999). Thus the provider must first identify and then evaluate the resources of new technologies, processes or products, new professional skills and potential organizational changes, with a view to consolidating and completing the current elements of its business.

Finally, integrating the two value chains also implies the harmonization and coordination of the organizational structure, operational procedures and routines, and the values and cultures underlying the business exercises. It also implies "harmonizing" the leading people belonging to the two organizations. Key company figures will be called to integrate with each other in the organizational mechanisms for interface, necessary for the correct management of relations in whatever type of outsourcing, for its entire duration. In this regard, Dyer and Singh (1998) assert that the possibilities for allied partners to generate "relational advantages" through sharing of 
complementary strategic resources increases with the greater compatibility in their organizational systems, processes and culture.

A frequent reason for failure to achieve cost savings (given equal quality of performance under outsourcing or insourcing) or of unsatisfactory levels of performance obtained through the provider market (given a predefined cost) is found in the basic strategic framework of the provider chosen, and thus the market strategy adopted. This type of failure can occur in two ways.

First, the provider could equally adopt either a "contract orientation" (typical of transactional marketing) or a "renewal orientation" (typical of relational marketing). In the first case, the provider is primarily motivated by the aim of arriving at the stipulation of an outsourcing contract, which will also permit pursuance of his own objects. In the second case, the provider's relational propensity actually serves as an important asset to the client firm for the protection of his objectives in the outsourcing choice.

Second, the provider's entrepreneurial offer could equally be characterized by a strategy taking a "marketing oriented" approach, centered on the satisfaction of needs as specifically stated by the client, or by a "product oriented" approach. In the second case, the objective of the provider basically to sell or impose his product or service, achieved under a logic of standardization. In the successive structuring and execution of the relationship, the provider will then demonstrate little availability to differentiate and flexibility in the product for the purposes of the contract objectives. We can conceive of a hypothetical example were the provider operates on a vast scale with a logic of standardization in the offer. In these circumstances, it is highly probable that the provider will result us unsatisfactory in terms of differentiation and flexibility in the offer, which the client will often request.

In conclusion, the client firm's understanding of the strategic logic of the provider's business and market approach is thus a further important moment of ex ante evaluation of the capacity of a given provider to provide satisfactory results for the client's business needs. The client's capacity for such evaluation is thus an essential instrument in addressing risks.

The analysis of relational needs is clearly much more complex than the analysis of subjective requisites, where the outsourcing firm can resort to quantitative measurement and from this develop comparative ratings of potential providers. For identification and evaluation of the relational requisites there is no analogous possibility. This means the evaluation of relational requisites can only be conducted at the qualitative level, making it a critically challenging factor in the final choice of the vendor.

\section{Contract Management and Relational Governance}

A second area where relational resources reveal their critical importance is in the stage of structuring the client-vendor relationship and creating the organizational conditions to control the execution of the contract on the part of the provider. Again in this area, the partnership-based approach requires the identification of organizational solutions for the client-vendor interface that will render the cooperative intent operational and concrete, effectively activating the search for new knowledge and innovation.

Since in strategic outsourcing the aim is co-generation of new shared knowledge, our observation is that it will not be sufficient to only define the contractual rules for the coordination of the two parties' actions. Instead it is necessary to create the organizational conditions that can ease the sharing of knowledge and the integration of the client and provider firms' value chains.

Here, the most important implication in terms of structuring the outsourcing relationship is the need to go beyond the purely contractual terrain and search for forms of regulation that revolve around a shared search for advantages and development in the respective businesses. In other terms, the shift from transactional to relational logic renders the area of contract engineering insufficient, at times unsatisfactory or even counterproductive, to obtain long-term results in innovation and creation of new knowledge. In this regard, McIvor (2005) shows how the "relational contracting" requires much more than the stipulation of a formal contract. It includes the activation of "social mechanisms" to permit the development of information exchanges, flexible interaction and joint resolution of the problems that arise from time to time in the relationship. Similarly, Han, Lee, and Seo (2007: p.31) state that "the interactions between the clients and their service providers often go beyond rules, agreements and exceptions; they also depend on intangible factors that cannot be easily incorporated into a contract".

The legal instrument of the "contract" thus cannot be considered as the only instrument to apply in striving to meet the needs for coordination and integration between the two parties (Behrens, 2006; Leimeister, 2010). The initial regulation of the exchanges within relationships is only a first, although necessary level in their structuring. The relationship must also find other mechanisms of interaction and coordination that permit the possibility of long-term evolution of the partnership. 
In taking a relational approach, the organizational tools for management of the relationship change. The instruments or no longer based simply on contractual norms, but now extend to formal and informal mechanisms of coordination that ease the common activity, both in its planning and implementation (Fitzgeral, \& Willcocks, 1994; Huai, 2008). The development of the new knowledge and innovation that characterize strategic IT outsourcing cannot be governed by contractual regulation alone (norms, clauses and detailed technical specifications), but instead require further elements:

- The true desire for interaction;

- The possibility for both parties to develop their businesses through the relationship:

- Strategic and organizational conditions for the integration and coordination of the respective businesses.

It is thus indispensable to come to a new logic in establishing the relationship between the interacting parties, including in part through a different conception of the contract itself, the source instrument in the regulation of the relationship. The contract must be understood as an instrument for interaction in the partnership, and not simply as a tool to regulate the commercial instruction. In the next section we illustrate how in strategic IT outsourcing, the contract must be structured in such a way as to be an instrument for flexibility, and not of rigidity.

\subsection{The Contract as "Risk Factor"}

The contract is usually seen as an "tool for risk control" in outsourcing, or rather as an set of rules and conditions that shelter the client firm from risks of opportunistic behavior and distancing of the provider's performance from the client's expectations or from what is predetermined by the stipulated terms (Gellings, 2007; Leimeister, 2010). There are different types of contracts in function of the objectives and aim of the IT outsourcing relationship, oscillating between the two opposing characteristics of rigidity and flexibility. Contracts are also termed as "tight" or "loose" (Grover, \& Teng, 1993). A tight contract leaves low margins of maneuver to the two parties. A loose contract is less formalized and rigid, intended to structure conditions for greater flexibility and adaptability with potential changes in the internal or external conditions that can affect the contract objectives.

A tight contract intuitively represents a higher degree or risk of inadequacy in meeting the changing conditions surrounding the activity defined under the contract. This will result in needs to frequently redefine the terms of the relationship, generating one of the many types of "hidden costs" (Larsen et al., 2013).

However it is also true that a contract providing numerous legal norms and the definitions of the contractual terms (performance objectives, criteria and parameters for control, sanctions in case of inadequacy, etc.) offers means of "defense" and "control" for the client firm in regards to the provider's operations. This is especially true where there is strong information asymmetry between the two parties, and thus with potential opportunistic behavior.

From this discussion we observe that the type of contract adopted must be closely linked to the type of outsourcing, in terms its aim and objectives. For strategic IT outsourcing the contract must function in the creation of a client-vendor partnership, and thus take a "loose" form, leaving margins for the provider's action and reciprocal adaptation between client and vendor. If not, the contract is actually transformed from a "tool for risk control" to a "risk factor". In fact it very often happens that in the desire to exercise greater control and defend against potential opportunistic provider behaviors, the client firm specifies the contract to the greatest extent possible, ultimately rendering it excessively rigid and blocking the development of a true partnership. On the contrary, a "loose" contract offers advantages of flexibility, making it possible to adapt to conditions that cannot be perfectly foreseen ex ante, and thus minimizing risks of inadequacy. In addition, flexibility in the contract permits the client to exploit the innovative capacity of his provider, since the provider is freer to express his competencies and specializations through proposal of solutions that were unknown and unforeseeable at the moment of stipulating the contract.

For this reason, in strategic IT outsourcing the contract must from the outset provide for procedures of change management. It must foresee what mechanisms and means will permit proceeding, in successive moments, to the revision of the outsourcing and its redirection towards characteristics of greater adequacy and coherence with respect to changing internal and external conditions, and in consideration of new business needs for the client. According to Barthélemy (2001), this doesn't imply that the contractual clauses are "vague" or "indeterminate". Instead it means conceiving and using the set of rules and conditions agreed between client and vendor in a flexible manner,

In strategic IT outsourcing, the "tight" contract can also become a "risk factor" for another important reason, arising from the means, parameters and intensity through which the client firm controls the provider. In our 
opinion, a pressing and bureaucratic type of control to achieve rigid respect of the contract's predefined and codified norms and procedures can result as counterproductive. It can produce effects of "flight from control", or "subjection to control", where the provider shows greater preoccupation with satisfying the control criteria and successive levels rather than with responding to the client's true needs through the achievement of the defined objectives.

Contrarily, the role of control systems should be to serve in the achievement of the fixed objectives, meaning that they should be oriented towards control of the results obtained. Outcomes should in fact be analyzed at the double level of analyzing the results/objectives and results/resources relationships. Rather than structure a system to control the providers' behavior under a hierarchical type of relationship, the client firms must consider the provider as an actor in a partnership relationship. The relationship is founded not only the sharing of objectives, but also on equal governance of the relationship itself. This includes the governance of the moments of controlling the relationship results and the provision of corrective interventions as necessary to realign the relationship in the desired direction.

The achievement of this ambitious result cannot be achieved without the existence of three essential elements:

- Mutual trust, achieved through positive evaluation of the presence of elements such as transparency, respect for undertakings assumed, absence of opportunistic behavior;

- Mutual esteem, achieved through positive evaluation of the professional competencies of the partner, which translate into capacities to arrive at the predefined objectives;

- A relational network, determined by the type and quality of relations that the two parties succeed in shaping under the organizational means identified for the relationship identified for the achievement of the contractual relationship.

\section{Conclusion and Future Developments}

This paper focuses on strategic IT outsourcing, meaning the externalization of functions, activities or processes that are closely tied to the company's core business and thus have high strategic value and strong impact on the creation of value. In this type of outsourcing, the relationship that develops between the client and vendor is best understood under a partnership-based or relational-based paradigm, where relational resources are seen as playing a crucial role. The paper contributes to existing research and literature on IT outsourcing, providing conceptual insights on the role of relational resources and their impact on mechanisms of governance in the client-vendor relationship.

In particular, we have analyzed relational resources from the view of risk management, and as an instrument to address risk. We have shown that almost all the risks generated by strategic IT outsourcing (except for those concerning erroneous decisions on if and what to externalize) are concentrated in three stages of the process: in choosing the provider, in contract management and in the ongoing management of the relationship. In these stages, relational resources are crucial to success in any outsourcing intended "for value creation".

Beginning from this conceptual framework, we focused consideration firstly on the choice of the provider, showing how traditional evaluation of the "subjective requisites" for potential providers is insufficient to ensure the development of a relationship of client-vendor partnership. We thus advanced the idea that in addition to the subjective requisites for the potential provider it is also necessary to identify and evaluate "relational requisites", which we consider as preconditions for evolution of a win-win relationship. Among these, we identify the following as crucial:

- The potential for perfect integration of the "value chains" of both parties in the relationship. The activity, function or process externalized must be coherent and functional with respect to the core business of the IT provider. It is insufficient that what the client requests simply be "doable" on the part of the provider.

- A strategic approach by the provider based on a "relational marketing" framework, rather than simply transactional marketing. Where the provider takes a relational marketing approach he is interested in "renewal of the contract", and will thus demonstrate availability to satisfy the customer's needs in a flexible manner, both in the initial stage of contract management and in execution of the contract. Where the provider takes a transactional marketing approach he is interested in the "stipulation of the contract", which he will try to define according to his objectives and needs rather than according to the objectives and needs of the outsourcer firm. Thus it is important that the analysis of relational requisites include an examination of the provider's ability to demonstrate a relational marketing approach, in order to ultimately develop a true partnership. 
- The potential for perfect integration of the organizational structures, procedures and human resources of both parties in the relationship. Many of the "hidden costs" in IT outsourcing develop in the course of executing the relationship. At this stage, in the absence of capacities for integration, difficulties and problems will arise in attempting to coordinate and harmonize the organizational context (structures, processes, people), and these will block the achievement of objectives for both parties.

- In the second place, we have illustrated how the contract is generally not a sufficient instrument for the evolution of a true partnership. Alongside the "contractual norms" there is also a necessity for "relational norms". These permit governance of a series of intangible factors that are essential in a mid to long term relationship of partnership: mutual trust, mutual respect, flexibility, information exchange and solidarity. In addition, not only is the contract likely to be insufficient as the sole instrument for regulation between the parties, it could actually revert from its intended role as the "instrument to address risk" to a "factor generating risks" in IT outsourcing. This happens when the contract is primarily an attempt to define a balance of terms and conditions that would protect the two parties from negative events or potential conflicts. Under this approach, the contract serves only as a rigid instrument for regulation of the parties' relationship, and fails to provide the characteristics of flexibility necessary in evolution of a true partnership. Thus the contractual governance of the relationship must be structured in a manner that guarantees the flexibility called for under conditions of a changing environment and the client's changing business needs. In terms of providing for such flexibility, we have illustrated two aspects:

- Provision of other mechanisms of formal and informal governance that ease the coordination and the joint performance of outsourcing planning and operations, to stand alongside standard "contractual governance". Such mechanisms can include: "relational governance", founded on principles of sharing, cooperation, mutual trust, commitment, and information exchange; the definition of processes to be developed jointly; linkage between organizational structures; the definition of roles and organizational units; identification of tasks for achievement of integration and coordination; governance based on systems of risk/reward incentivization, which share the risks and profits inherent in the relationship between the two parties.

- Provision for procedures of change management in the contract, from the outset of its development. This means the identification of mechanism and means that could be used in subsequent moments, for ongoing revision and realignment of the contract to better and more coherently adapt to changing environmental conditions and the new business needs of the outsourcer firm.

The current paper develops these considerations in purely conceptual terms, providing deeper understanding of the role of relational resources in IT outsourcing. Our considerations lead above all to insights that provide support to the company's in its tasks of choosing an IT provider and in defining the governance mechanisms for the relationship. Further research at both the conceptual and empirical levels could provide additional constructive contributions. At the conceptual level, it would be useful to analyze the different roles of relational resources in the various typologies of IT outsourcing (business process outsourcing, application outsourcing, infrastructure technology outsourcing). Research at the empirical level could investigate if and how the choice of firms' providers in IT outsourcing takes account of "relational requisites" for the potential provider: in particular what variables are actually used in the company processes of selection and choice. A second useful line of empirical research would be to investigate what formal and informal mechanisms of governance are used in the subsequent stages: of contract management and ongoing management.

\section{References}

Aris, S. R. H. S., Arshad, H., \& Mohamed, A. (2008). Conceptual framework on risk management in IT outsourcing projects. Information Science \& Applications, 4(5), 816-831.

Aron, R., \& Liu, Y. (2005). Determinants of operational risks in global sourcing of financial services: evidence from field research. Brooking Trade Forum 2005, 373-398. https://doi.org/10.1353/btf.2006.0002

Bahli, B., \& Rivard, S. (2005). Validating measures of information technology outsourcing risk factors. The International Journal of Management Science, 33. https://doi.org/10.1016/j.omega.2004.04.003

Beasley, M., Bradford, M., \& Dehning, B. (2009). The value impact of strategic intent on firms engaged in information systems outsourcing. International Journal of Accounting Information Systems, 10, 79-96. https://doi.org/10.1016/j.accinf.2008.08.001

Behrens, S. (2006). Governance and information systems outsourcing: a contingency perspective, in Lehner, F., Nosekabel, H. \& Kleinschmidt, P. (Eds.), Multikonferenz Wirtschaftsinformatik, 101-116. Passau. 
Bensaou, M. (1999). Portfolios of buyer-supplier relationships. Sloan Management Review, 40(4), 35-44.

Barthélemy, J. (2001). The hidden costs of IT outsourcing. Sloan Management Review, 42(3), 60-69.

Barthélemy, J. (2003). The seven deadly sins of outsourcing. Academy of Management Executive, 17(2). https://doi.org/10.5465/AME.2003.10025203

Chou, D. C., \& Chou, A. Y. (2011). Innovation outsourcing: Risks and quality issues. Computer Standards \& Interfaces, 33(3), 350-356. https://doi.org/10.1016/j.csi.2010.10.001

Das Aundhe, M., \& Mathew, S. K. (2009). Risks in offshore IT outsourcing: A service provider perspective. European Management Journal, 27, 418-428. https://doi.org/10.1016/j.emj.2009.01.004

Dyer, J. K., \& Singh, H. (1998). The relational view: Cooperative strategy and sources of interorganizational competitive advantage. Academy of Management Review, 23(4).

Earl, M. J. (1996). The risk of outsourcing IT. Sloan Management Review, 37(3).

Eisenhardt, K. M. (1989). Agency theory: An assesment and review. The Academy of Management Review, 14(1).

Emerson, R. M. (1972). Exchange theory, Part I: A psychological basis for social exchange, in Berger, J., Zelditch, M., \& Anderson, B. (Eds.), Sociological Theories in Progress, 2. Boston: Houghton-Mifflin.

Fitzgeral, G., \& Willcocks, L. (1994). Contracts and partnerships in the outsourcing of IS. Proceedings of 15th International Conference on Information Systems.

Gellings, C. (2007). Outsourcing relationship: the contract as IT governance tool. Proceedings of the 40th Hawaii International Conference on System Sciences. https://doi.org/10.1109/HICSS.2007.421

Gobble, M. M. (2013). Outsourcing innovation. Research-Technology Management, 56(4), 64-67. https://doi.org/10.5437/08956308X5604005

Goles, T., \& Chin, W. W. (2002). Relational Exchange theory and IS outsourcing: developing a scale to measure relationship factors, in Hirschleim, R., Heinzl, A., \& Dibbern, J. (Eds.), Information Systems Outsourcing, 221-250. Berlin: Springer. https://doi.org/10.1007/978-3-662-04754-5_11

Gonzalez, M. R., Gasco, J. L., \& Llopis, J. (2010). Information systems outsourcing reasons and risks: a new assessment. Industrial Management \& Data Systems, 110(2). https://doi.org/10.1108/02635571011020359

Gottschalk, P., \& Solli-Saether, H. (2006). Maturity model for IT outsourcing relationships. Industrial Management \& Data Systems, 106(2), 200-212. https://doi.org/10.1108/02635570610649853

Greaver, M. F. (1999). Strategic outsourcing. A structured approach to outsourcing decisions and initiatives. New York: Amacom.

Grover, V., \& Teng, J. T. C. (1993). The decision to outsource information systems function. Journal of Systems Management, 44(11), 34-38.

Han, H. S., Lee, J. N., \& Seo, Y. W. (2007). Analyzing the impact of a firm's capability on outsourcing success. A process perspective. Information \& Management, 45, 31-42. https://doi.org/10.1016/j.im.2007.09.004

Huai, J. (2008). Mitigating outsourcing risk through relational contract. Proceedings of Fourth International Conference "Wireless Communications, Networking and Mobile Computing", School of Economics \& Management, East China Jiaotong University, Nanchang. https://doi.org/10.1109/WiCom.2008.1593

Homans, G. C. (1958). Social behavior as Exchange. American Journal of Sociology, 63(6), 597-606. https://doi.org/10.1086/222355

Homans, G. C. (1961). Social behavior. Its elementary forms. Harcourt Brace Jovanovich, in Leimester, S. (2010), IT outsourcing governance. Client types and their management strategues. Gabler Verlag.

Ikediashi, D. I., Ogunlana, S. O., Boateng, P., \& Okwuashi, O. (2012). Analysis of risks associated with facilities management outsourcing: A multivariate approach. Journal of Facilities Management, 10(4), 301-316. https://doi.org/10.1108/14725961211265756

Joshi, A. W., \& Stump, R. L. (1999). Determinants of commitment and opportunism: Integrating and extending insights from Transaction Cost Analysis and Relational Exchange Theory. Canadian Journal of Administrative Sciences, 16(4), 334-352. https://doi.org/10.1111/j.1936-4490.1999.tb00693.x

Kamanth, R. R., \& Liker, J. K. (1994). A second look at Japanese product development. Harvard Business Review, November-December. 
King, W. R. (2005). Outsourcing and offshoring: the new IS paradigm? Journal of Global Information Technology Management, 8(2), 1-4. https://doi.org/10.1080/1097198X.2005.10856393

Kishore, R., Rao, H. R., Nam, K., Rajagopalan, S., \& Chaudhury, A. (2003). A relationship perspective on IT outsourcing. Communication of the Association for Computing Machinery, 46(12), 87-92. https://doi.org/10.1145/953460.953464

Kraljic, P. (1983). Purchasing must become supply management. Harvard Business Review, 5.

Lacity, M., \& Willcocks, L., (2014). Business process outsourcing and dynamic innovation. Strategic Outsourcing: An International Journal, 7(1), 66-92. https://doi.org/10.1108/SO-11-2013-0023

Larsen, M. M., Manning, S., \& Pedersen, T. (2013). Uncovering the hidden costs of offshoring: The interplay of complexity, organizational design, and experience. Strategic Management Journal, 34(5), 533-552. https://doi.org/10.1002/smj.2023

Lee, J. N. (2001). The impact of knowledge sharing, organizational capability and partnership quality in IS $\begin{array}{lllll}\text { outsourcing success. Information } \& \text { Management, } & 38, & 323-335 .\end{array}$ https://doi.org/10.1016/S0378-7206(00)00074-4

Lee, J. N., Miranda, S. M., \& Kim, Y. M. (2004). IT outsourcing strategies: Universalistic, contingency, and configurational explanations of success. Information Systems Research, 15(2), 110-131. https://doi.org/10.1287/isre.1040.0013

Leimeister, S. (2010). IT outsourcing governance. Client types and their management strategies. Gabler Verlag. https://doi.org/10.1007/978-3-8349-6303-1

Logan, M. S. (2000). Using Agency Theory to design successful outsourcing relationships. International Journal of Logistics Management, 11(2), 21-32. https://doi.org/10.1108/09574090010806137

Macneil, I. R. (1985). Relational contract: What we do and do not know. Wis. L. Rev., 483.

Macneil, I. R. (1986). Exchange revisited: Individual utility and social solidarity. Ethics, 96(3), 567-593. https://doi.org/10.1086/292776

McIvor, R. T. (2005). The outsourcing process: strategies for evaluation and management. Cambridge: Cambridge University Press. https://doi.org/10.1017/CBO9780511543425

Mol, M. J., van Tulder, R. J. M., \& Beije, P. R. (2005). Antecedents and performance consequences of international outsourcing. International Business Review, 14, 599-617. https://doi.org/10.1016/j.ibusrev.2005.05.004

Nam, K., Rajagopalan, S., \& Chaudhury, A. (1996). A two-level investigation on information system outsourcing. Communication of the Association for Computing Machinery, 39(7), 36-44. https://doi.org/10.1145/233977.233989

Popoli, P. (2011). IT services offshoring: opportunities and critical factors from a strategic perspective, in Information Systems and New Applications in the Service Sector: Models and Methods, 1(3), 240-258. Pennsylvania, USA: IGI Global, Hershey.

Poppo, L., \& Zenger, T. (2002). Do formal contracts and relational governance function as substitutes or complements?. Strategic Management Journal, 23, 707-725. https://doi.org/10.1002/smj.249

Qi, C., \& Chau, P. Y. K. (2012). Relationship, contract and IT outsourcing success: evidence from two descriptive case studies. Decision Support Systems, 53, 859-869. https://doi.org/10.1016/j.dss.2012.05.018

Quinn, J. B., \& Hilmer, F. (1994). Strategic outsourcing. Sloan Management Review, Summer.

Schmeisser, B. (2013). A systematic review of literature on offshoring of value chain activities. Journal of International Management, 19(4), 390-406. https://doi.org/10.1016/j.intman.2013.03.011

Stuckey, J., \& White, D. (1993). When and where not to vertically integrate. Sloan Management Review, Spring.

Thibaut, J. W., \& Kelley, H. H. (1959). The social psychology of groups. Wiley, in Leimester, S. (2010), IT outsourcing governance. Client types and their management strategies. Gabler Verlag.

Williamson, O. E. (1985). The economic institutions of capitalism. New York: The Free Press.

Williamson, O. E. (1986). The economic institutions of capitalism. Firms, markets, relational contracting. New York: The Free Press.

Williamson, O. E. (1996). The mechanism of governance. Oxford University Press. 
Wind, J., \& Cardozo, R. N. (1974). Industrial market segmentation. Industrial Marketing Management, April. https://doi.org/10.1016/0019-8501(74)90025-X

Yanhong, W. (2011). A framework of business process outsourcing relationship evolution model. Management Science and Industrial Engineering, 2011 International Conference on, 995-999. https://doi.org/10.1109/MSIE.2011.5707581

Yeo, C., \& Saboori-Deilami, V. (2017). Strategic challenges of outsourcing innovation in global market. Asia Pacific Journal of Innovation and Entrepreneurship, 11(1), 5-16. https://doi.org/10.1108/APJIE-04-2017-017

Zhang, Q., \& Kurien, J. (2017). A comparative empirical study on determinants of IT offshore outsourcing to China and India as recipient countries. Information Technologies and International Development, 1(2), 21-37.

\section{Copyrights}

Copyright for this article is retained by the author(s), with first publication rights granted to the journal.

This is an open-access article distributed under the terms and conditions of the Creative Commons Attribution license (http://creativecommons.org/licenses/by/4.0/). 